\title{
Uusi näkökulma alttaritaulujen Kristus-kuvaan
}

\section{Hanna Pirinen}

Ringa Takanen, Laupeus ja inhimillisyys. Naisten ääni, affektiiviset elemuodot ja ikonografinen murros suomalaisissa alttaritauluissa vuosina 1870-1920. Turun yliopiston julkaisuja, sarja C, 494 (Turku: Turun yliopisto, 2020). https://www.utupub.fi/bitstream/ handle/10024/150212/Annales\%20C\%20494\%20Takanen $\% 20$ VK.pdf? sequence $=1$ \&isAllowed $=y$

Naisista tuli 1800-luvun jälkipuoliskolla merkittäviä toimijoita monilla yhteiskunnan lohkoilla, myös kuvataiteessa. Tämä osoitetaan alttaritaulujen osalta Ringa Takasen Turun yliopistossa tarkastetussa taidehistorian väitöskirjassa Laupeus ja inhimillisyys. Naisten ääni, affektiiviset elemuodot ja ikonografinen murros suomalaisissa alttaritauluissa vuosina 1870-1920. Alttaritaulut ovat esimerkkejä tekijöidensä niihin lataamista merkityksistä, ja ne osoittavat tilaajiensa käsityksen julkisen taiteen aiheeksi sopivista teemoista. Kuuden artikkelin lisäksi artikkeliväitöskirjan kokonaisuuteen kuuluu laaja johdantoluku. Väitöskirjan kohteena on pariinkymmeneen Kristuksen inhimillisyyttä ja sosiaalista toimijuutta kuvaava sekä naisiin ja lapsiin teemallisesti rajattu alttaritauluaineisto.

Haasteen Takasen soveltamalle historiallisesti kontekstoivalle otteelle tarjoaa panofskylainen peruskysymys siitä, onko alttaritaulun aihe oire jostakin? Tarkastelussa on aiherypäs, jossa kuvakerronnallisesti keskeisintä on Kristus-hahmon vuorovaikutus kuvattujen hahmojen mutta myös katsojan kanssa. Alttaritaulujen Kristus ja kussakin aiheessa kuvatut muut hahmot asettuvat sommitelmaan osoituksina taiteilijan intentioista ja pyrkimyksistä levittää haluamaansa viestiä, olipa kyse sitten laupiaasta Kristuksesta langenneen naisen armahtavana kohtaajana tai kanssakärsijänä ja lohduttajana, kuten Getsemane-aiheissa. Kuvatulkinnallisesti taideteosta tarkastellaan myös historiallisena dokumenttina ja lajityyppinsä edustajana. Miten teos kuvastaa syntyaikaansa, sitä yhteisöä ja yhteiskuntaa, jossa se on syntynyt? Takanen yhdis- tää tutkimusasetelmaansa myös katsojan, visuaalisen kulttuurin tarkastelutapaa noudatellen.

Tieteellisessä tutkimuksessa menetelmät korvautuvat toisilla, mutta myös palaavat uusiutuneina tai kriittisesti uudelleenarvioituina sovelluksina. Näin on käynyt noin sadan vuoden takaisen "näkijän", taidehistorioitsija ja kulttuuriteoreetikko Aby Warburginkin (1866-1929) kohdalla. Häneltä periytyvä paatosmuodon käsite ja kuvien kulttuurisen vaellushistorian sovellus ovat esimerkkejä taidehistorioitsijoiden työkalupakkiin pitkään kuuluneen tarkastelumenetelmän elastisuudesta ja sovellettavuudesta nykytutkimuksessakin. Kerronnallista näkökulmaa soveltavan väitöskirjakokonaisuuden ansiokkain anti on kuvien lähiluvussa ja kuvasisältöjen tulkinnassa. Takanen asettaa kriittisesti tulkintamenetelmien vaiheet ja painotukset keskinäiseen keskusteluun. Hän luonnehtii tutkimustaan uskonnollisten ihmiskuvien ja elemuotojen analyysiksi. Kuvien lähiluennassa huomiota on kiinnitetty kuvattujen hahmojen liikkeisiin, eleisiin ja ilmeisiin. Tässä Takanen jatkaa liikekielen ja kuvakerronnan periaattei- 
ta tutkineen akateemisen opettajansa professori Altti Kuusamon oppien perustalta. Tärkeän juonteen Takasen tavassa tarkastella uskonnollisaiheisten inmishahmojen kehonkieltä ja ilmeitä muodostaa affektin ja affektiivisuuden käsitteiden soveltaminen. Näitä käsitteitä käytetään merkitsemässä, miten teos tunnetasolla joko tietoisesti tai tiedostamatta vaikuttaa katsojaan. Affektiivisyyttä analysoiva ote toimii warburgilaisittain tunteen ilmaisun psykoikonografiana.

Tarkastelutapaansa vertailevaksi kulttuuritieteeksi luonnehtineen Warburgin mielestä yksityiskohdat ovat paljastavia ja juuri niissä piili oivallusten ydin. Takasen väitöskirjan kuvamateriaalin nopea läpikäynti nostaa esiin yhden toistuvan yksityiskohdan: valkoisen jättiläisliljan. Tapaus on kiinnostava esimerkki kasvista ajan ja aatteiden ilmentymänä. Kristillisessä ikonografiassa valkoinen lilja tulkitaan puhtaan synnittömyyden symboliksi esimerkiksi Kristuksen tai Neitsyt Marian yhteydessä. Mariologisessa perinteessä lilja liittyy myös hellyyteen ja lempeyteen. Takasen alttaritauluaineistossa lilja esiintyy hämmästyttävän usein. Se toistuu Alexandra Frosterus-Såltinin (1837-1916) alttaritauluissa, ja kukoistaa samaan aikaan niin saksalaisten Nasareenien raamatullisaiheisissa teoksissa kuin mitä moninaisimmissa 1800 -luvun lopun henkisissä yhteyksissä. Valkoinen jättiläislilja oli yksi spiritistisissä materialisoimisnäytöksissä konkreettisen hahmon ottaneista kasveista. Selittämättömästi tuon- puoleisesta ilmestynyt lilja jätti katsojat inmetyksen valtaan Suomessakin vierailleen Elizabeth Reedin, taitelijanimellä Madame d'Espérancen (1855-1919) Göteborgissa järjestetyssä näytöksessä. ${ }^{1}$

\section{Alttaritaulut tutkimuskohteena}

Suomalaisiin alttaritauluihin ja niiden kristilliseen kuvastoon liittyvää relevanttia tutkimusta on tehty vuosikymmeniä. Jyväskylän yliopiston taidehistorian oppiaineessa on 1980-luvulla aloitetun hankkeen tuloksena koottu laajat systemaattiset tiedostot ja kuva-arkisto alttaritauluista ja kirkollisesta kuvataiteesta. Tutkija pääsee nykyisellään tekemään aineistovalintoja ilman työlästä peruskartoitusvaihetta näiden arkistoaineistojen monipuolisten hakuominaisuuksien avulla. Oleellisimpia saman aihepiirin aikaisempia suomalaistutkijoita ovat taidehistorioitsijat Heikki Hanka, Jorma Mikola, Pirjo Juusela ja Helena Hätönen. Ruotsalaisista uskonnollisen taiteen tutkijoista Hedvig Brander Jonsson ja Mabel Lundberg ovat käsitelleet ajallisesti samaa kautta. Pääsääntöisesti julkaisut ovat parinkymmenen vuoden takaa lukuun ottamatta Mikolan vuonna 2015 julkaistua taidehistorian väitöskirjaa Alttarilta alttarille: Alttaritaulumaalaus Suomessa autonomia-ajan loppupuolella. Alttaritaulututkimus on siis astumassa uuteen vaiheeseen näkökulmaistettujen teemoittelujen ja monitieteisten tulkintakehikoiden tuoreuttamana. ${ }^{2}$

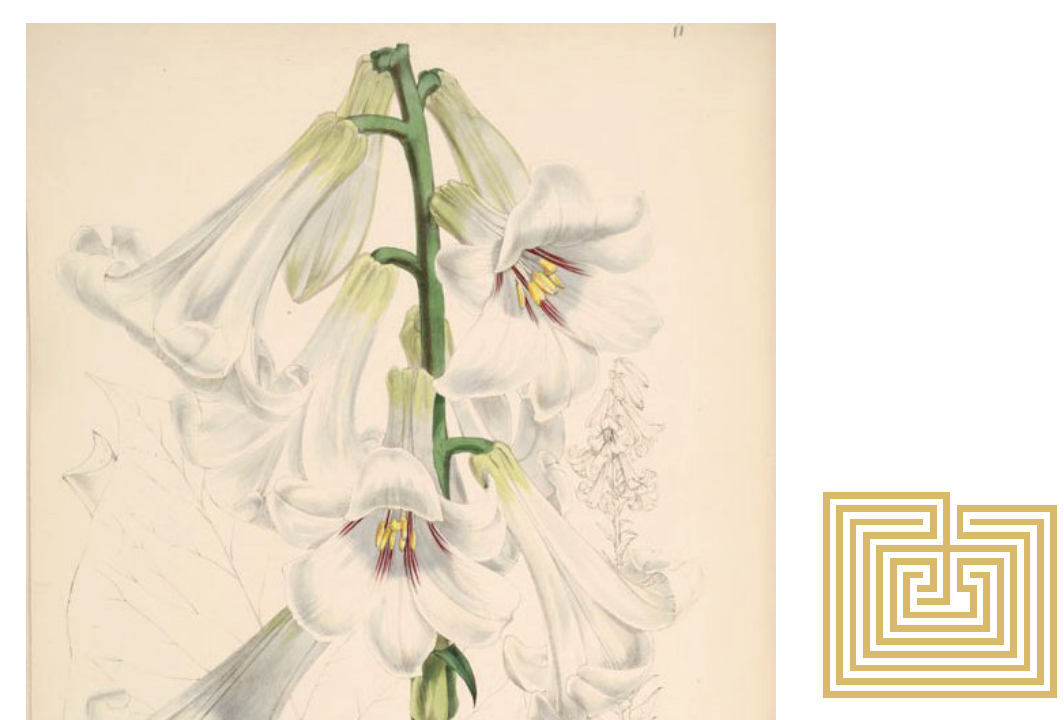

Kuva 1. Jättiläislilja (Kuva Walter Hood Fitch, Cardiocrinum giganteum, teoksessa Henry John Elwes, A monograph of the genus Lilium (London: Taylor and Francis, 1880) Kuvalähde: https://commons.wikimedia.org/wiki/File:Cardiocrinum_giganteum.jpg\#/media/File:Cardiocrinum giganteum.jpg 
Naisiin, lapsiin ja Kristuksen henkilökohtaiseen kohtaamiseen ja hänen inhimilliseen olemukseensa liittyvät aiheet olivat uusia tulokkaita alttaritauluaiheistossa 1800-luvun jälkipuoliskolla. Uudistumisesta huolimatta kaikista 1800-luvun alttaritauluaiheista suurin osa esitti ristiinnaulittua Kristusta ja ehtoollisen asettamista. Kristus Getsemanessa ja Kristus rukoilee vuorella -aiheet toivat henkilökohtaisesti koetun tuskan ja ihmisyyden entistä vahvemmin esiin. Takasen valitsemien teemojen mukaan koottu alttaritauluaineisto osoittaa erityisesti Alexandra Frosterus-Såltinin merkityksen uuden aiheiston soveltajana. Kristuksen ilmestyminen Maria Magdalenalle, Kristus ja kanaanilainen nainen sekä Kristus ja syntinen nainen siirsivät painopistettä uudella tavalla naishahmoon, jonka feminiinisyys ja seksuaalisuus eivät kuuluneet aikaisemmin suomalaisen alttaritaulutaiteen teemoihin. Samarialainen nainen ja Magdalan Maria olivat alkaneet aiheina esiintyä Pariisin salongissa 1860-luvulla. Frosterus-Såltin omaksui uuden kuvaston, ja hän osoittautuu Takasen tarkastelussa aktiiviseksi naisia, lapsia ja uudenlaista Kristus-kuvaa välittävän taiteen puolestapuhujaksi. Todisteena tästä ovat ne hankintatapaukset, joissa tilaaja alun perin toivoi ristiinnaulittu-aiheista alttaritaulua, mutta taiteilija teki ehdotuksen itselleen mieluisammasta aiheesta, jonka tilaaja sitten hyväksyi.

\section{Naisnäkökulma alttaritauluihin}

Naishistorian tutkimus on ollut vireää historiatieteissä. Siitä muodostuukin tieteidenvälinen kohtaamispiste
Takasen tutkimusasetelmassa. Artikkelit täsmentävät sitä, miten uudenlaisen yhteiskunnallisen kutsumuksen toteuttaminen avasi myös tavallisille naisille mahdollisuudet toimintaan kotiin rajautunutta elämänpiiriä laajemmalle 1800-luvun jälkipuoliskolla. Varsinkin sivistyneistöperheissä, mutta laajemminkin, alettiin panostaa entistä enemmän myös tyttöjen koulutukseen. Naisia tuettiin hakeutumaan taidekoulutukseen. Kotimaiset koulutusrakenteet suosivat sukupuolten tasa-arvoa, eikä edes ulkomaisia opintoja estetty naisilta. 1800-luvun lopussa läpimurtonsa tehneiden naistaiteilijoiden vaiheet tunnetaan Riitta Konttisen käynnistämien systemaattisten tutkimusten ansioista.

Alttaritaulujen aiheet kontekstoituvat Takasen tutkimuksessa erityisesti naisiin kristillis-sosiaalisen työn toimijoina, ja näin tarkastelussa painottuu yhteiskunnallisten ja moraalisten arvostusten muutosta käsittelevä suomalainen naishistoriantutkimus. Pirjo Markkola, Anne Ollila ja Marjo-Riitta Antikainen ovat tutkimuksillaan osoittaneet, miten naisten roolit muuttuivat ja miten eri yhteiskuntaluokista lähtöisin olevien naisten tehtäväksi tuli laupeudentyön perinnön uudistaminen ja haavoittuvassa asemassa olevien, kuten sairaiden, lasten ja moraalisesti langenneina pidettyjen huomioiminen. Epäkohtien parantamiseksi naiset ottivat vastuuta raittiusliikkeessä, osallistuivat prostituutiokeskusteluun ja diakoniatyöhön. Pienten lasten päivähoito organisoitiin aloittamalla lastenseimitoimin- ta, ja aktiivisille naisille avautui sosiaalityön tehtäviä uusissa asutuskeskuksissa käynnistetyn ns. kaupunkilähetyksen piirissä. ${ }^{3}$

Uskonto- ja kirkkohistoriallisen tutkimuksen tuorein anti ja tämän aineksen soveltaminen jää Takasen taustoituksessa kristillis-sosiaalista aspektia ohuemmaksi myös käsitteellisellä tasolla. Murroksellisen 1800- ja 1900-luvun vaihteen henkisten virtausten tutkimus on Turun yliopistossa ollut viime vuosina erittäin vireää. Totuuden etsijät -tutkimusryhmän jäsenet ovat julkaisuillaan tuoneet tutkimustilanteen uuteen vaiheeseen. Monet kuvataiteeseenkin vaikuttaneet virtaukset kytkeytyvät vuosisadan vaihteen kansainvälisen ilmapiirin ja kotimaisten yhteisöjen vaikutusverkostoihin. Nina Kokkisen lisäksi monet Turun yliopiston piirissä toimivat tutkijat, kuten Marjo Kaartinen, Tiina Mahlamäki ja Maarit Leskelä-Kärki ovat ansioituneet viime vuosina ansiokkaasti 1800-luvun henkisten virtausten ja taiteen yhteyksien tutkimuksessa. ${ }^{4}$ Vaihtoehtohenkisyyden, esoterian ja spiritualismin tuleva tutkimus toivottavasti täsmentää myös laajempaa kuvaa aikakauden mentaliteetista ja yksilöiden henkilökohtaisista reflektioista, esimerkiksi raittiusliikkeen vaikutuksesta ihmiskuvaan ja kuvataiteen sisältöihin.

On kuitenkin harmi, ettei Takanen ole ottanut syvällisemmin tarkasteluun esimerkiksi orientalismin tai esoteeristen piirteiden erittelyä tarkastelemissaan alttaritauluissa. Jopa kansikuvaksi valittu Alexandra

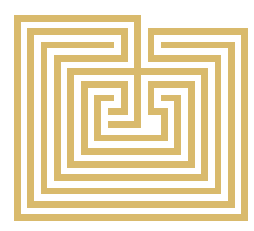




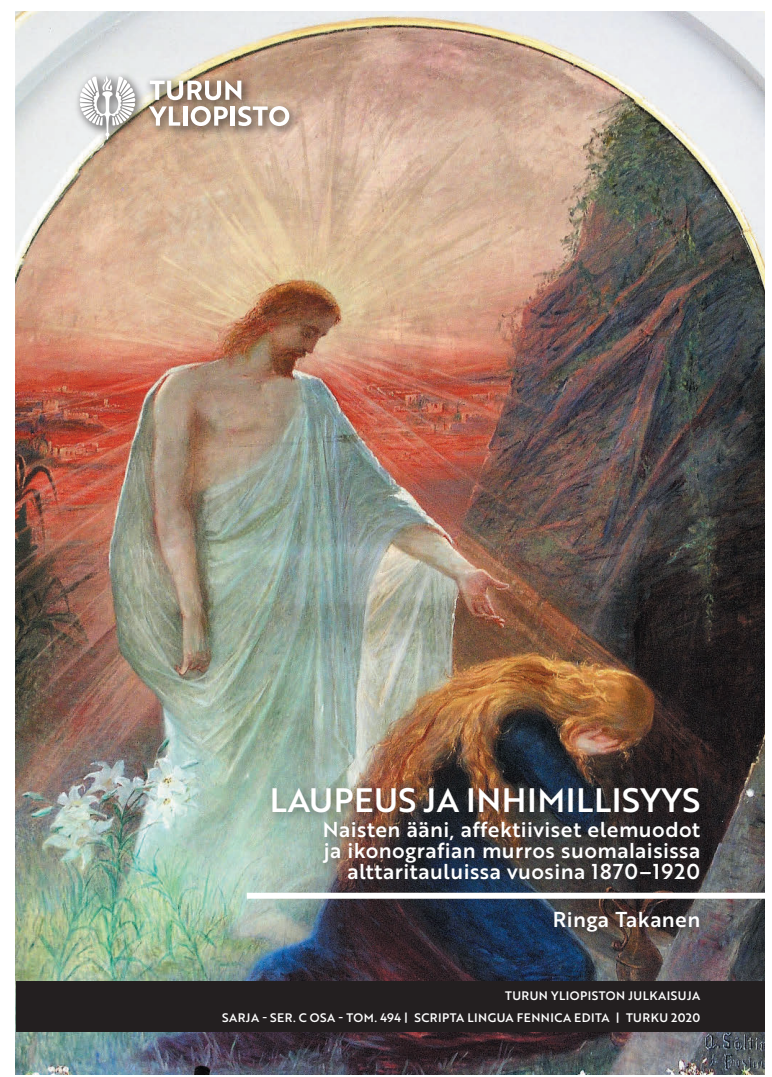

Kuva 2. Ringa Takasen väitöskirjan kansi. Alexandra Frosterus-Såltin, Kristuksen ilmestyminen Maria Magdalenalle, Jepuan kirkon alttaritaulu, Uusikaarlepyy. Kuva: Heikki Hanka.
Frosterus-Såltinin maalaama Jepuan alttaritaulu olisi saanut syvyyttä vielä tarkemmasta lähiluvusta. Maalauksessa itämaisen aamuruskon punassa kylpevä Jerusalem nimittäin toistaa populaaria ja romantisoitua orientalistista kuvaustapaa. Henkistynyttä tietoisuutta esitettiin esoteeristen oppien mukaisessa inmiskuvauksessa auraattisella säteilyllä; samaa voi tunnistaa Jepuan alttaritaulun lempeästä Jeesuksesta, joka on kuvattu poikkeuksellisen aktiivisena kohdentamassa huolenpitonsa surevaa Magdalan Mariaa kohtaan. Vastaavia piirteitä voi osoittaa monista aineistoon kuuluvista teoksista. Esimerkiksi ajan virtauksia herkästi omaksunut Venny Soldan-Brofeldt (1863-1945) otti vaikutteita suurten venäläisten mestareiden Kristus-kuvauksista, ja näin erityisesti hänen Getsemane-aiheissaan näkyvät yhteydet esimerkiksi Ivan Kramskoin taiteeseen.

\section{Akateemisen maalaustaiteen perinne}

Naisaiheet, naisten tekemä taide ja keskeiset taiteilijat, kuten Alexandra Frosterus-Såltin ja Venny Soldan-Brofeldt - jotka nousevat toimijoina näkyvimmin esiin käsitellystä kuva-aineistosta - ovat oireellinen merkki ajastaan. Molemmilla oli kotitaustanaan naisten koulutukseen kannustavasti suhtautunut perhe, ja heille toiminta yhteiskunnan hyväksi oli johtava juonne elämäntehtävässä. 1800-luvun jälkipuoliskon naistaiteilijoilla oli rohkeutta ryhtyä alttaritaulujen kaltaisiin monumentaalimaalaushankkeisiin. Haastavimmillaan tehtävä oli suuren kertovan useista hahmoista koostuvan kokonaisuuden sommittelu.

Düsseldorfissa ja Pariisissa kotimaisten opintojen ohella taidekoulutusta saaneen Alexandra Frosterus-Såltinin kohdalla on kiinnostavaa se, miten hän omaksui perustan monifiguuriseen sommitelman rakentamisen akateemisen taiteen perinteestä. Frosterus-Såltinin kuvakerronnalla on yhteys hänen opettajansa düsseldorfilaisprofessori Otto Mengelbergin (1817-1890) taiteeseen. Molempien historia-aiheille ovat tyypillisiä akateemiset kuvaamisen konventiot elekielessä ja kasvojen ilmeissä. Tällaisten piirteiden tunnistamiseen taidehistorialla on vakiintunut menetelmä, vertaileva muotoanalyysi, jolla voidaan osoittaa yhtäläisyydet viivankäytössä, materiaalien esittämisen tavassa ja liikkeen kuvauksessa. Piirtämisen tapa on paljastavin tietyn aikakauden esittämiskaavan osoittaja, ja se kuvastaa taidekoulutuksessa omaksuttuja periaatteita ja tyylillisiä esikuvia. Ihmiskuvauksessa eleet ja ilmeet ovat paljastavia, sillä niitä tarkastelemalla voidaan havaita taiteilijoiden akateemisessa koulutuksessaan omaksumia hahmojen tunteiden ilmaisua ohjanneita säännöstöjä.

Kertovat raamatulliset teemat kuuluvat maalaustaiteen perinteisimpään kategoriaan. Niin Mengelbergin kuin Frosterus-Såltininkin esitystapaa ja kerronnan kieltä ohjanneet esitysnormit tunteiden kuvauksessa ja katsojan tunteisiin vetoamisessa olivat vakiintuneet jo 
1600-luvun lopussa erityisesti ranskalaisen akatemiataiteen piirissä.

\section{Uudistuva visuaalinen maailma}

Taiteellinen työskentely graafisten esikuvien pohjalta oli vuosisatainen käytäntö. 1800-luvun jälkipuoliskolla kuvajäljenneteollisuus syötti markkinoille valtaisan määrän kristillistä kuvastoa. Harmillista Takasen väitöskirjan kannalta on, ettei tieteellisesti kunnianhimoista taidehistoriallista tutkimusta 1800-luvun jälkipuoliskon kristillisaiheisen taiteen suurten suosikkien kansainvälisestä vaikutuksesta juurikaan ole. Vähät julkaistut tutkimukset väittelijä on onnistunut löytämään. Syy marginaalisuuteen on, että painoteollisuuden levittämää kuvastoa on pidetty sentimentaalisena ja liian populaarina.

Kristillinen kuvasto yhtenäistyi kaikkialla, minne läntinen kristillinen sivistys oli ulottanut otteensa 1800-luvun jälkipuoliskolla. Arvostetut teokset olivat aikansa akateemisten mestareiden, kuten Carl Blochin, Heinrich Hofmannin, Ary Schefferin, Emil Liskan tai Ernst Hildebrandin teosten jäljenteitä. Vastaavasti Bertel Thorwaldsenin Kristus-veistoksen kipsikopiosta tuli suosittu.

Koteihin ja rukoushuoneisiin hankittiin painokuvia ja kuvajäljenteitä kirjakaupoissa saatavilla olevien luetteloiden mukaan. Painotuotteita välittivät myyntiin kaupallisten toimijoiden ohella myös erilaiset kristilliset järjestöt, kuten saksalainen Verein zur Verbreitung religiöser Bilder, joka toimi Düsseldorfin nasareenitaiteilijoiden piirissä aktiivisesti 1800-luvun jälkipuoliskolla levittäen valtaisan määrän kuvajäljenteitä. Alttaritaulukuvasto onkin hämmästyttävän samankaltaista niin Pohjois-Euroopassa kuin YhdysvalIoissa tai Australiassa tuona aikana.

Yhtenäistyneen kansainvälisen kuvamaailman hahmottaminen on jäänyt väitöskirjakokonaisuuden artikkelien ulkopuolelle. Takanen toki tuntee ja osoittaa eri yhteyksissä malleja, mutta ei tee tästä modernin reproduktion aikakauden ilmiöstä laajempaa katsausta. Tuotteliaan Alexandra Frosterus-Såltinin samoin kuin useiden muidenkin taiteilijoiden alttaritaulujen ominaispiirteet olisivat kuitenkin selittyneet täsmällisemmin, jos kuvajäljenneteollisuus ja 1800-luvun uusi populaari uskonnollinen kuvasto olisi huomioitu laajuudessaan. Aihepiiri on tällä hetkellä eräs kiinnostavimmista kulttuurihistoriallisesti operoivan populaarivisuaalisuuden alueista, jolla toimii esimerkiksi saksalaisvetoinen kansainvälinen tieteellinen työryhmä Forum BildDruckPapier.

\section{Hyvä, paha artikkeliväitöskirjamuoto}

Artikkeliväitöskirjat ovat alkaneet yleistyä viime vuosina myös taidehistorian piirissä. Ringa Takanen on oppiaineensa pioneeri Turun yliopistossa. Prosessimaisesti etenevään väitöskirjatutkimukseen artikkeliväitöskirja sopii mainiosti, sillä se mahdollistaa laajan tutkimusasetelman pilkkomisen mielekkäiksi osaprojekteiksi esimerkiksi stipendikausiin sovittaen. Näin on menetelty tämänkin väitöskirjatyön kohdalla.
Takasen artikkeliväitöskirjan johdanto vastaa hyvin tehtäväänsä kokonaisuutta avaavana ja perustelevana kriittisenä katsauksena, jossa käydään keskustelua keskeisimmistä kuvantutkimuksen menetelmistä. Tutkimusasetelman eri lohkot eritellään johdonmukaisesti artikkeleissa esiin nostettujen teemojen ja teoreettisen kehikon kanssa keskustellen. Niin ikään siinä kootaan artikkelien tulokset. Menetelmäkehikon keskeisten ainesten toistuminen artikkelista toiseen tuo tarkastelutapaan varsin vähän vaihtelua. Niin ikään jo julkaistujen artikkeleiden sisällön synteettisempi reflektointi ja asettaminen kriittiseen keskusteluun esimerkiksi henkisten virtausten osalta on jäänyt kypsyttelemättä paljolti artikkelimuodosta johtuen.

Ringa Takasen artikkeleista koostuva väitöskirja on tekstinä sujuvaa ja selkeää asiaproosaa, ja näin se soveltuu kaikille alttaritaulutaiteesta ja kuvantulkintamenetelmistä kiinnostuneille lukijoille. Kuvituksen laatu vaihtelee, joskin vastuu tästä kuuluu lähinnä artikkeleiden julkaisijaorganisaatioille. Taidekuvan erityisvaatimuksiin ei ole kiinnitetty riittävää huomiota kaikissa toimituskunnissa. 


\section{Viitteet}

1 Marjo Kaartinen, Spiritistinen istunto (Helsinki: Suomalaisen Kirjallisuuden Seura, 2020).

2 Jorma Mikola, Alttarilta alttarille: Alttaritaulumaalaus

Suomessa autonomia-ajan loppupuolella.

Jyväskylä: University of Jyväskylä. http://urn.fi/

URN:ISBN:978-951-39-6166-4.

3 Pirjo Markkola, Synti ja siveys: Naiset, uskonto

ja sosiaalinen työ Suomessa 1860-1920 (Helsinki:

Suomalaisen Kirjallisuuden Seura, 2002); Anne Ollila,

Jalo velvollisuus: Virkanaisena 1800-luvun lopun

Suomessa. Helsinki: (Suomalaisen Kirjallisuuden

Seura, 1998); Marjo-Riitta Antikainen, Sääty,

sukupuoli, uskonto: Mathilda Wrede ja yhteiskunnan

muutos 1883-1913. Helsinki: Suomalaisen

Kirjallisuuden Seura, 2003); Eevan tie alttarille:

Nainen kirkon historiassa. Minna Ahola, Marjo-Riitta

Antikainen \&Päivi Salmesvuori (toim.) Helsinki: Edita,

2002).

4 Moderni esoteerisuus ja okkultismi Suomessa.

Tiina Mahlamäki, Nina Kokkinen (toim.) (Tampere:

Vastapaino, 2020)
FT, dos. Hanna Pirinen toimii Jyväskylän yliopistossa taidehistorian yliopistotutkijana. Hän on erikoistunut kirkolliseen taideperinteeseen ja monitieteiseen taideteostutkimukseen.

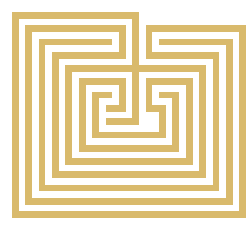

